\title{
MONITORIA EM SALA: \\ UMA AÇÃO DE FORMAÇÃO DOCENTE
}

\author{
Elisa Novaski Cordeiro* \\ Jeniffer Imaregna Alcantara de Albuquerque* \\ Fernanda Deah Cbichorro Baldin ${ }^{* * *}$
}

RESUMO: O presente texto analisa respostas de alunos do curso de Letras Português-Inglês, os quais atuaram como monitores-alunos em sala no Português para Falantes de Outras Línguas (PFOL), da Universidade Tecnológica Federal do Paraná, Campus Curitiba (UTFPR-CT). O artigo busca identificar as visões dos alunos-monitores sobre a relevância da sua participação na monitoria do PFOL da UTFPR-CT. Para isso, organizamos o texto da seguinte maneira: primeiramente, apresentamos a organização do artigo, imprimindo a ideia geral e expondo as partes que constituem tal estudo. Em seguida, discorremos sobre textos legais e institucionais sobre monitoria e damos voz à nossa perspectiva de trabalho com a monitoria em sala de aula. Logo, estabelecemos relações entre monitoria e formação de professores, recorrendo a Lave e Wenger (2001) e Johnson e Golombek (2016) no que diz respeito à aprendizagem situada, à Schön (1992), Pérez Gómez (1992), Gimenez (2005), Halu (2010) e Zamboni (2013) acerca de suas visões sobre professor reflexivo e, mais especificamente, aos conceitos de reflexão na ação e reflexão sobre a reflexão na ação, de Schön (1992). A metodologia utilizada foi um questionário aberto, com 12 perguntas, a partir da perspectiva interpretativista (LESSA DE OLIVEIRA, 2008; NEVES, 2015). As análises revelam que a atividade de monitoria faz ressoar questões teórico-práticas da graduação em Letras (as quais, muitas vezes não são tratadas dentro grade curricular do curso). Além disso, embora encontremos pontos de contato entre as respostas, também observamos identidades particulares em cada um deles.

PALAVRAS-CHAVE: PFOL; Monitoria em sala; Identidades docentes; Formação de professores.

\section{Introdução}

A presente discussão se inscreve na agenda de pesquisas e ações desenvolvidas no Programa de Extensão Universitária Português para Falantes de Outras Línguas (doravante PFOL), da Universidade Tecnológica Federal do Paraná, Campus Curitiba (UTFPR-CT).

\footnotetext{
* Doutora em Estudos Linguísticos pela Universidade Federal do Paraná (UFPR). Professora Titular da Universidade Tecnológica Federal do Paraná (UTFPR).

${ }^{* *}$ Doutora em Psicolinguística pela Universidade Federal do Rrio Grande do Sul (UFRGS). Professora Assistente da Universidade Tecnológica Federal do Paraná (UTFPR).

*** Doutoranda em Estudos Linguísticos pela Universidade Federal do Paraná (UFPR). Mestre em Estudos Literários pela mesma Instituição. Professora adjunta da Universidade Tecnológica Federal do Paraná (UTFPR). 
As ações hoje desenvolvidas em tal programa tiveram sua origem no Projeto em PFOL da UTFPR em 2001, em virtude da necessidade da própria instituição em receber estudantes intercambistas (BALDIN e CORDEIRO, 2017). Ao longo do tempo, o projeto foi crescendo e ampliando suas atividades, tendo alcançado o título de Programa de Extensão dentro da UTFPR, em 2019. Por entender que um Programa de Extensão deve também promover reflexões críticas sobre/no ensino e pesquisa, o PFOL atua no desenvolvimento de ações que visam à integração da comunidade interna e externa da universidade, tendo alcance e associação entre dois públicos específicos: 1) alunos estrangeiros que precisam de aulas de português (alunos e não alunos da UTFPR) e 2) alunos brasileiros, acadêmicos do curso de Letras Português-Inglês da UTFPR, os quais atuam como monitores em sala de aula. Tal modo de trabalho confere ao PFOL aliar aspectos práticos e teóricos do Curso de Letras por meio da formação inicial de professores. É sobre este último público que a presente discussão se debruça.

De modo a assumir uma formação de professores na qual a prática pedagógica seja sempre crítica e se faça presente em todos os anos da licenciatura, mobilizamos alguns conceitos que embasam nossa proposta. Primeiro, apresentamos e discutimos a Lei de Diretrizes e Bases da Educação Nacional (LDB), no 9394, de 20 de dezembro de 1996, para trazer entendimentos legais e pedagógicos acerca da atividade de monitoria dentro do Ensino Superior. Em seguida, refletimos sobre a atividade de monitoria em sala de aula a partir da concepção de aprendizagem situada de Lave e Wenger (1991), de forma a buscar meios de aplicá-la à realidade do cenário de aprendizagem situada na formação de professores de línguas (JOHNSON e GOLOMBEK, 2016). Por fim, discorremos sobre a monitoria em sala de aula do PFOL como uma forma de formação profissional reflexiva, a partir das leituras de Schön (1992); Pérez Gómez (1992); Gimenez (2005); Halu (2010) e Zamboni (2013).

Para a análise, dialogamos com as respostas providas pelos monitores do PFOL da UTFPR-CT, as quais foram obtidas a partir da aplicação de um questionário aberto, gerado em 2017. O objetivo desse recorte específico foi o de identificar visões dos alunos-moni- 
tores sobre a relevância da sua participação na monitoria em sua formação como professores. Tratando-se das respostas de alunos de uma graduação em Letras Português-Inglês, os dados operam como um meio de refletir sobre/no português e em relação ao processo da monitoria como um instrumento para a melhoria do ensino de graduação, representando uma oportunidade de vivenciar o cotidiano de sala de aula, ao desenvolver uma postura investigativa e reflexiva.

\section{Monitoria: conceitos}

O sistema universitário federal brasileiro foi instituído em 1968, pela Lei Federal $n^{\circ}$ 5.540, de 28 de novembro, que buscava regulamentar esse sistema. Em seu Artigo 41, foi disposta a monitoria acadêmica, sistematizando as regras para sua existência. $\mathrm{O}$ texto do artigo afirma o seguinte:

As autoridades deverão criar as funções de monitor para os alunos do curso de graduação que se submeterem a provas específicas, nas quais demonstrem capacidade de desempenho em atividades técnico-didáticas de determinada disciplina. Parágrafo único. As funções de monitor deverão ser remuneradas e consideradas título para posterior ingresso em carreira de magistério superior. (BRASIL, 1968, sem página)

Essa Lei foi revogada pela Lei de Diretrizes e Bases da Educação Nacional (LDB), n ${ }^{\circ}$ 9394, de 20 de dezembro de 1996, que no Título VII - Das Disposições Gerais [Do Ensino Superior], o Artigo 84 assevera que: “Os discentes da educação superior poderão ser aproveitados em tarefas de ensino e pesquisa pelas respectivas instituições, exercendo funções de monitoria, de acordo com seu rendimento e seu plano de estudos" (BRASIL, 1996, sem página).

Embora a lei de 1968 tenha sido revogada e substituída pela Lei de Diretrizes e Bases da Educação Nacional, de 1996, é interessante notar que, na versão anterior, explicita-se a relação entre ambas as formações do graduando, a saber: acadêmica e profissional. Parece haver a previsão de que ser monitor é uma das etapas essenciais para o "ingresso em carreira de magistério superior”. Comparativamente, as Leis parecem tecer considera- 
ções distintas a respeito da importância do ser monitor, uma vez que a de 1996 traz explanações mais gerais sobre o cargo de monitoria, sem enfatizar seu papel na formação do graduando.

Apesar das diferenças políticas e pedagógicas entre as Leis, as Instituições de Ensino Superior (IES), em geral, hospedam programas de monitoria de modo a atrelá-los aos projetos de incentivo à docência, com o intuito de oferecer uma reflexão sobre teoria e prática para o graduando-professor em pré-serviço. Assim, a partir da reflexão supracitada, entendemos que

A monitoria é uma modalidade de ensino e aprendizagem que contribui para a formação integrada do aluno nas atividades de ensino, pesquisa e extensão dos cursos de graduação. Ela é entendida como instrumento para a melhoria do ensino de graduação, através do estabelecimento de novas práticas e experiências pedagógicas que visem fortalecer a articulação entre teoria e prática e a integração curricular em seus diferentes aspectos, e tem a finalidade de promover a cooperação mútua entre discente e docente e a vivência com o professor e com as suas atividades técnico-didáticas. (UNIDERP apud RODRIGUES e SANTIAGO, p. 2, 2017)

Inúmeras IES possuem programas e projetos desenvolvidos por docentes e discentes-professores em serviço que procuram relacionar teoria e prática, sendo um deles a monitoria. No site da UTFPR, enunciam-se os seguintes objetivos para o programa de monitoria:

1. despertar no estudante o interesse pelo ensino e oportunizar a sua participação na vida universitária em situações extra-curriculares e que o conduzam à plena formação científica, técnica, cidadã e humanitária;

2. prestar o suporte ao corpo docente no desenvolvimento das práticas pedagógicas, no desenvolvimento de novas metodologias de ensino e na produção de material de apoio que aprimorem o processo ensino-aprendizagem;

3. prestar o apoio ao aprendizado do estudante que apresente maior grau de dificuldade em disciplinas/unidades curriculares e/ou conteúdo. (SITE DA UTFPR) ${ }^{1}$

\footnotetext{
${ }^{1}$ Disponível no link: < http://www.utfpr.edu.br/cursos/coordenacoes/graduacao/toledo/td-engenharia-de-bioprocessos-e-biotecnologia/area-academica/infraestrutura-de-apoio-academico/programa-de-monitoria $>$ 
A partir do excerto, é importante destacar como os eixos teórico-práticos elencados como objetivos da atividade de monitoria procuram trabalhar com a formação acadêmica, profissional e pessoal do graduando, conforme previsto pela Lei de 1968. Em especial, ao se observar o primeiro objetivo, chama-se atenção para a necessidade de possibilitar ao graduando a "plena formação científica, técnica, cidadã e humanitária". Tal excerto está intimamente relacionado com o trabalho feito no PFOL da UTFPR-CT, o qual abrange projetos como monitoria em sala de aula de PFOL. A grande demanda de alunos estrangeiros que precisam aprender o português brasileiro para sobreviver e (re)fazer sua vida no Brasil garante um público constante de atendimento para nossos alunos-monitores. Assim, conforme explicitado no site da UTFPR, sobre os objetivos da monitoria, a atividade confere aos graduandos participantes do PFOL a oportunidade de docência supervisionada com uma crescente realidade educacional: a inserção de migrantes refugiados e com visto de auxílio humanitário.

De acordo com o cenário exposto até o momento, observa-se a visão legal da atividade de monitoria e possibilidades pedagógicas. No entanto, um aspecto a ser investigado relaciona-se com a atuação do aluno-monitor durante as atividades em sala, uma vez que diretrizes como as da UTFPR não impõem que a monitoria deva acontecer obrigatoriamente fora da aula, ou seja, que o monitor atenda os alunos que monitora apenas em horários distintos do componente curricular para o qual foi selecionado. Assim, parece ser de escolha do professor orientador, em reuniões com o aluno-monitor, a logística da atividade de monitoria.

Apesar dessa questão logística parecer um aspecto menor em relação à discussão aqui levantada, ela se apresenta como um vital e distintivo ponto para a monitoria como atividade formativa para os alunos estrangeiros. Isso porque, durante as aulas de PFOL, principalmente, a reflexão sobre formação inicial dos graduandos de Letras acontece contingencialmente. É na vida da sala de aula que emergem as questões mais caras à formação e professores.

Assim, ao menos na UTFPR-CT, a monitoria das aulas de PFOL opera diferentemente das chamadas monitorias tradicionais ou comuns, em que o aluno-monitor atende 
outros alunos fora do momento da aula. A monitoria aqui discutida opera de maneira semelhante a propostas desenvolvidas por autores como Faria (2003). Essa autora propõe uma participação mais ativa e cooperativa dos atores do processo de ensino-aprendizagem ao enxergar que o acompanhamento e auxílio dos monitores devem ser realizados no interior da disciplina-alvo, uma vez que há a reflexão no espaço de atuação e a promoção do aprendizado na autonomia das ações do graduando. De acordo com Celani (2005), a participação de todos não é apenas um meio, mas é respeitada como um objetivo em si mesmo, pois tem como um fim último a emancipação. A partir desse enfoque, passa-se a pensar na monitoria como um espaço que procura atender às novas demandas da sociedade, que ecoa a necessidade de novas técnicas e modos de pensar-agir.

\section{A monitoria entendida a partir da aprendizagem situada}

Retomamos, então, as duas visões de monitoria estabelecidas na seção anterior: a primeira relacionada a uma atividade de reforço, realizada fora do ambiente de sala de aula, restringindo o trabalho do aluno-monitor a tirar dúvidas de quem tem dificuldades e o procura, e a segunda mais ativa e interativa, feita dentro de sala de aula, na qual o monitor acompanha todo o processo de planejamento, preparação da aula, seleção de material didático, execução em sala e avaliação dos resultados junto com o professor da disciplina. Nossa visão de monitoria se constitui neste segundo grupo apresentado (conforme explicitaremos de modo mais detalhado na próxima seção de Contextualização). Acreditamos, portanto, que a monitoria é um processo construído por meio da interação entre alunosmonitores, professor da disciplina e alunos atendidos, criando-se, dessa forma, uma rede pautada na diversidade natural das relações (SCHNEIDER, 2006) que é um processo de aprendizagem constituído como um ato social.

De acordo com Schneider (2006), a monitoria é um dos meios pelos quais o aluno em formação tem a chance de entrar em contato com a diversidade e, por meio da mediação propiciada pelo trabalho em equipe, tem uma formação mais significativa, abrindo-se à compreensão do outro, baseando-se no respeito ao diferente. Nessa perspectiva, pensamos que a atividade de monitoria configurada nesses moldes possibilita ao aluno-monitor uma 
aprendizagem vista e vivenciada como um ato social que prevê interação por meio da participação em práticas sociais consolidadas por um determinado grupo.

Além disso, uma das importantes diferenças entre a monitoria em sala e a monitoria fora de sala é a supervisão constante do professor, o que permite que conversas (orientações e discussões) possam ser feitas com base nas visões tanto do professor formador quanto do aluno-monitor, o que não é possível na monitoria fora de sala - uma vez que o professor orientador não se encontra junto ao monitor nos momentos de atendimento aos alunos.

Relacionamos, dessa maneira, nossa visão de monitoria e de aprendizado à teoria da “aprendizagem situada”, desenvolvida pelos estudiosos Lave e Wenger (1991). Esses pesquisadores propuseram um estudo tendo por base exemplos de profissionais diversos, tais como alfaiates, açougueiros, parteiras, todos envolvidos em suas atividades laborais cotidianas. Em diferentes relatos, é possível perceber que essas pessoas agem no mundo como membros de uma comunidade de prática ${ }^{2}$, ressaltando-se a relação entre a ação das pessoas e os ambientes nos quais elas se inserem, demonstrando uma importante relação entre os membros da comunidade, o processo de participação e o conhecimento produzido por meio de suas práticas.

A ação de aprender, portanto, é entendida como um processo que ocorre ao longo de um período de tempo, por meio da participação social em determinadas práticas de um grupo específico. Tal configuração resulta na formação de novos traços identitários em todos os membros do grupo, bem como na criação da sensação de pertencimento nos membros mais novos que vão sendo incorporadas nas práticas cotidianas (LAVE e WENGER, 1991).

Lave e Wenger (1991) definem a aprendizagem situada como uma teoria da prática social na qual a relação entre o indivíduo e o mundo ao qual ele pertence se constitui como

\footnotetext{
${ }^{2}$ Comunidade de prática é o termo utilizado pela teoria da aprendizagem situada para nomear um grupo de pessoas unidas por uma causa comum, seja um trabalho, estudo ou qualquer relação que dá a esse grupo uma identidade própria, assim como interesses e necessidades comuns (LAVE e WENGER, 1991).
} 
um processo de aprendizado em grupo. Na mesma perspectiva, Almeida (2013) define aprender, pensar e saber como relações construídas por pessoas em atividade "no mundo, com o mundo, e surgidas no mundo socialmente e culturalmente estruturado" (ALMEIDA, 2013, p. 31). Para o autor, analisar a aprendizagem dessa forma, como um processo de participação, ajuda a quebrar as tradicionais dicotomias: cérebro e corpo; contemplação e experiência. As pessoas, suas ações e seus mundos estão implicados em seu falar, conhecer e aprender.

$\mathrm{Na}$ área de formação de professores de língua, Johnson e Golombek (2016) embasam seus estudos na ideia de aprendizagem situada. Para elas, a aprendizagem se origina em um movimento que ocorre de fora para dentro, que não se caracteriza como direto, mas mediado.

A teoria da aprendizagem situada parte dos estudos de Vygotsky, que evidenciam a relação entre a mediação, por meio da interação, com o processo de desenvolvimento mental. De acordo com Vygotsky, a relação entre o homem e o mundo não é direta, mas sim mediada (JOHNSON; GOLOMBEK, 2016). Nessa direção, para que haja aprendizagem, é necessário haver interação.

Para complementar nosso posicionamento em relação à integração entre a concepção de aprendizagem situada, formação de professores e atividades desenvolvidas na monitoria, explicitaremos a formação docente de acordo com a abordagem de professor reflexivo. Tal perspectiva nos parece adequada, uma vez que buscamos proporcionar aos alunos a experienciação de situações reais de sala de aula, por meio da nossa concepção de monitoria, que busca integrar os alunos de Letras de modo ativo com as atividades relativas à docência, conforme explicaremos na próxima seção. Essa configuração cria espaços de discussão e reflexão entre monitores e professores a fim de pensar e repensar constantemente a dinâmica de sala de aula.

Os estudos sobre a formação profissional reflexiva têm origem nas pesquisas de Donald Schön na década de 1980, ganhando bastante força nos anos 1990 (PIMENTA, 2002) e sendo repensadas até a atualidade. $\mathrm{Na}$ área de formação de professores, o termo 
professor reflexivo foi ganhando cada vez mais espaço, tendo como ponto principal a seguinte questão: a importância da prática de sala de aula desde o começo do curso, aliada a uma atitude reflexiva. Sobre esse ponto, Gimenez (2005) define a formação de professores como:

(...) um processo de aprendizagem que leva em conta o aprendizprofessor e seus conhecimentos. Assim, a formação está sendo considerada naqueles contextos onde são oferecidas oportunidades para desenvolvimento com a presença de mediador mais experiente (seja na fase inicial seja na fase continuada) e ferramentas que possibilitem a articulação dos conhecimentos adquiridos ao longo de experiências anteriores e atuais. (...) A formação de professores tem sido um processo orientado para tomada de decisões. (GIMENEZ, 2005, p. 184)

Assim, a definição de formação de professores compreende momentos nos quais seja possível ao estudante encontrar-se com a prática de sala aula de modo real. Tendo contato com alunos e situações de aprendizagem reais, o acadêmico terá que buscar soluções e tomar decisões em relação a diferentes aspectos da prática didática: elaboração de material didático, planejamento, administração do tempo, organização da interação no momento da aula, etc. Todas essas questões são pensadas e refletidas entre o aluno-monitor e o professor da disciplina durante todo o processo de monitoria.

Nessa direção, Halu (2010) relaciona a prática reflexiva, a partir da experiência de sala de aula, com o desenvolvimento da capacidade de enfrentar diferentes situações diárias. Assim, o professor terá a oportunidade de levantar questões e de tratá-las por conta própria, pensando sozinho e com seu grupo de colegas professores. Segundo a autora, o professor formador seleciona e apresenta um campo de exploração inicial, criando condições e recursos básicos para que seus diferentes alunos possam explorar inúmeras situações a partir de seus próprios pontos de partida.

Explanando a questão da reflexão na profissão de professor, Schon (1992) descreve dois momentos importantes para o professor: 1) "reflexão na ação" e 2) "reflexão sobre a reflexão na ação". No primeiro momento, o docente sempre mantém uma postura de abertura para escutar e ver seu aluno, podendo ser surpreendido por constatar que o aluno não consegue realizar ou entender uma tarefa ou um conteúdo. Assim, o professor reflete sobre 
a situação no mesmo instante em que ela ocorre, tentando reformular seu modo de agir perante a situação a fim de auxiliar o aluno a superar suas dificuldades.

É importante frisar que a reflexão não se trata de uma mera técnica de atuação do docente, mas uma auto investigação, por parte do professor, no modo como ele resolve seus conflitos de sala de aula diariamente e o modo como integra seu conhecimento científico e suas ações em sala. Uma vez que cada situação com a qual o professor se depara é única, não existe, portanto, uma fórmula dizendo como agir, a decisão sobre como agir dependerá do próprio professor, através de seu poder de reflexão sobre a circunstância (ZAMBONI, 2013; PÉREZ GÓMEZ, 1992).

O segundo momento descrito por Schon (1992) que sucederia a reflexão na ação seria a "reflexão sobre a reflexão na ação". Trata-se de o professor refletir, depois de sua aula, sobre o modo como lidou com o acontecimento vivenciado em sala, e sobre o modo como agiu para resolver a situação pela qual passou. De acordo com o autor, esse processo de lançar um olhar retrospectivo sobre o que ocorreu também se caracteriza como uma ação. Zamboni (2013) caracteriza esse processo como a reflexão que guia a ação: o docente vai refletindo sobre suas diferentes possibilidades de tomada de decisão e vai, cada vez mais, aperfeiçoando seu poder de análise durante e após as situações de sala de aula.

A diferença básica entre os dois movimentos descritos é que no primeiro, "reflexão na ação", a reflexão ocorre durante a prática e tem efeitos imediatos, já no segundo movimento, "reflexão sobre a reflexão na ação", a reflexão ocorre depois da prática e tem um efeito a longo prazo. Segundo Schön (1992), a chave para que os professores reflitam na e sobre a ação é a experenciação da prática já em sua formação.

\section{Contextualização do PFOL na UTFPR-CT}

Conforme já esclarecido na seção de Introdução, o PFOL é um Programa de Extensão da UTFPR-CT. Becker et al (2011) datam a origem do PFOL na UTFPR-CT em 2001 com o objetivo de atender a uma demanda de alunos estrangeiros que vinham para intercâmbio de alguns meses na UTFPR-CT. Em 2008, surge o Curso de Licenciatura em 
Letras Português Inglês e, a partir de então, as aulas de português para intercambistas passam a integrar os licenciandos de Letras Português-Inglês, com atividades de monitoria em sala (Becker et al, 2011). Além dos intercambistas, passa-se a atender comunidade de estrangeiros externa à universidade.

Entre 2013 e 2014, mais professores do Departamento Acadêmico de Línguas Estrangeiras Modernas (DALEM) da UTFPR-CT começam a se envolver com o PFOL e a demanda de alunos estrangeiros da comunidade externa à universidade aumenta a cada semestre. Então, o PFOL se estrutura na universidade como um projeto de extensão e passa a ofertar 5 turmas regulares de PFOL (PFOL 1, 2, 3, 4 e 5), intensificando a integração entre licenciatura e extensão, por meio de participação de um maior número de licenciandos como monitores.

Em 2016, o curso de Letras Português Inglês (licenciatura dupla) é descontinuado e são abertos dois cursos: Letras Português e Letras Inglês, ambos de licenciatura simples. O segundo passa a ser gerido pelo DALEM, juntamente com o então Projeto de Extensão do PFOL. O novo curso de Letras Inglês traz em sua organização curricular três disciplinas de PFOL: Ensino de PFOL 1, Ensino de PFOL 2 e Grupo de Pesquisa em PFOL.

Essa nova configuração garante uma integração ainda maior entre os licenciandos e o PFOL e as atividades de monitoria se intensificam tanto dentro de sala de aula quanto fora dela. São regularizados encontros de formação entre os alunos-monitores, além das reuniões semanais com os professores orientadores, e também passam a ser organizados variados encontros de socialização entre alunos e professores brasileiros e os estrangeiros atendidos nas aulas de PFOL (comunidades externa e interna da UTFPR-CT), tais como exibição de filmes com posterior debate, encontros para ouvir e conhecer músicas, literatura, discussões sobre programas de televisão, festas temáticas.

Em 2019, o projeto é submetido a uma comissão avaliadora especial na UTFPRCT e se transforma no Programa de Extensão PFOL UTFPR-CT, mantendo uma agenda ativa que contempla não só a oferta de aulas em turmas regulares semestrais de 60 horas de português para estrangeiros, como também uma série de eventos cujos objetivos principais são 1) proporcionar opções de lazer (utilizando português) para os estrangeiros que, 
em geral, tem um círculo de interação restrito com brasileiros; 2) envolver os alunos de Letras Inglês na organização e execução desses eventos a fim de proporcionar-lhes uma formação pautada na diversidade e no respeito ao outro que se mostra diferente de mim, conforme proposto na definição de monitoria definida por Schneider (2006).

Essa breve retrospectiva da atuação do grupo ao longo dos últimos anos, especialmente a partir de 2008, tem o objetivo de fazer entender como, aos poucos, o PFOL foi construindo suas ações de monitoria entendendo esse como um processo de integração entre aspectos teóricos e prática didática, sempre por meio da constante conversa e reflexão entre professores orientadores e alunos monitores.

Os alunos que se interessam pela monitoria, primeiro passam pela observação em sala: eles acompanham uma turma específica com uma professora orientadora. Uma vez por semana, há um encontro entre professora e aluno-monitor para falar sobre a aula observada naquela semana, sobre o planejamento para as próximas aulas, sobre a seleção e organização do material didático e sobre outras questões que sejam pertinentes. Na medida em que os monitores observam as aulas e vão participando de atividades de interação em pequenos grupos com os alunos estrangeiros, durante a aula, o professor vai lhe dando algumas tarefas: pensar em atividades para um tema específico de uma aula, organizar partes de uma aula, corrigir uma atividade e, por fim, até o final do semestre de monitoria, espera-se que o aluno-monitor planeje, execute e avalie uma aula completa (sempre sob supervisão da professora orientadora). A participação do monitor em todas essas atividades é sempre planejada entre professora orientadora e aluno-monitor, dependendo de quanto o monitor se sente preparado para participar.

Atualmente, temos 2 tipos de monitoria: voluntária e com bolsa, no caso da primeira, não fazemos qualquer restrição em termos de período do curso que o aluno-monitor esteja cursando ou experiência em outras atividades de monitoria ou mesmo com ensino de línguas estrangeiras. Ou seja, o critério é a vontade do estudante de Letras em participar do PFOL. Na monitoria remunerada, como as bolsas são em número menor do que os candidatos a elas, a seleção é feita via edital. 
Nossa pesquisa apresenta dados gerados no ano de 2017. O objetivo desse recorte específico foi o de identificar visões dos alunos-monitores sobre a relevância da sua participação na monitoria em sua formação como professores. Para isso, passamos agora à explicitação da metodologia da pesquisa.

\section{Metodologia}

Nosso estudo traz dados gerados no ano de 2017. Procuramos verificar como os monitores expressavam suas vivências e mudanças na constituição do ser professor a partir da monitoria no PFOL. Na época da geração de dados, todos os monitores eram voluntários e cursavam o curso de Letras Português Inglês (então em fase de descontinuidade). Nesse sentido, a pesquisa enquadra-se em um viés de investigação qualitativo e interpretativista. Na mesma esteira de pesquisadores como Lessa de Oliveira (2008) e Neves (2015), entendemos que o pesquisador qualitativo e interpretativista sempre baseia suas considerações acerca do mundo real a partir da interpretação que faz de um conjunto de experiências vividas pelos indivíduos que observa. Lidamos, neste artigo, com as interpretações de respostas dos alunos-monitores, os quais, por sua vez, também interpretam o seu contexto de vivência de modos particulares. Parece-nos fundamental caracterizar os participantes da pesquisa e a organização da geração de dados, que é o que fazemos a seguir.

$\mathrm{Na}$ época de geração dos dados, seis monitores participavam do PFOL, e conforme já enunciamos, todos eram voluntários. Quatro deles responderam a um questionário aberto composto por 12 questões que constituiu a geração de dados.

A faixa etária dos quatro monitores participantes do estudo era entre 18 e 21 anos e eles haviam participado até aquele momento do PFOL durante dois a quatro semestres. Todos estavam em diferentes períodos do curso, o que permitia uma práxis múltipla e compartilhada, isto é, como os alunos-monitores estavam em diferentes momentos do curso, isso lhes fornecia diferentes possibilidades para analisar e interpretar as suas vivências em sala de aula com os alunos estrangeiros. 
Optamos por usar como letra inicial de identificação dos participantes a letra "M", de "monitor" e números de um a quatro para representar os alunos-monitores e suas respectivas vivências e interpretações de suas atuações no contexto do PFOL.

O Quadro 1 apresenta algumas informações dos participantes desta pesquisa.

Quadro 1 - Informações dos participantes da pesquisa.

\begin{tabular}{|c|c|c|c|c|}
\hline Informação & M1 & M2 & M3 & M4 \\
\hline Idade & 19 & 20 & F & 20 \\
\hline Sexo & $\mathrm{F}$ & $\mathrm{M}$ & $5^{\circ}$ & $\mathrm{F}$ \\
\hline $\begin{array}{c}\text { Período no curso de Letras } \\
\begin{array}{c}\text { Tempo de monitoria no PFOL } \\
\text { em semestre(s) }\end{array}\end{array}$ & 2 & $3^{\circ}$ & 2 & $4^{\circ}$ \\
\hline $\begin{array}{c}\text { Experiência com docência fora } \\
\text { do PFOL }\end{array}$ & Nenhuma & Nenhuma & $\begin{array}{c}\text { 1 ano com cursinho } \\
\text { pré-vestibular }\end{array}$ & Nenhuma \\
\hline
\end{tabular}

Fonte: as autoras (2020).

É importante ressaltar que no momento da geração dos dados, três dos participantes não possuíam experiência formal como docentes, ou seja, não ministravam aulas particulares ou em centros de idiomas. Apenas a participante M3 possuía alguma experiência em sala, uma vez que ministrava aulas como professora voluntária em um curso preparatório para os exames do Enem e vestibular local. Contudo, ainda sim, o contexto em que ela atuava era bastante diverso do existente no PFOL.

A geração de dados se deu a partir de um questionário de 12 perguntas abertas, as quais procuravam levar os alunos a refletirem sobre suas experiências como monitores. Os questionamentos buscavam compreender os seguintes itens: como os monitores se sentiam na posição de professor; quais seriam os conhecimentos mobilizados para atender às demandas dos alunos estrangeiros; quais conhecimentos precisariam ainda ser desenvolvidos, na visão deles, para sua formação docente.

Buscando oferecer um ambiente mais flexível de respostas para os participantes, optamos por colocar o questionário em formato Google Forms. O questionário ficou aberto por um período de duas semanas, em junho de 2017, para que os participantes pudessem responder. 
A partir da descrição da metodologia empregada na pesquisa, passamos à análise dos dados.

\section{Análise dos dados gerados}

Conforme apresentamos na seção de Metodologia, o questionário constava de 12 perguntas. Por questões de espaço e recorte desta pesquisa, selecionamos 3 para análise. A seleção foi feita seguindo o critério de verificar, em suas respostas, a importância e o impacto da monitoria em sua construção como professor. Por isso, as respostas analisadas referem-se à trajetória do aluno-monitor de PFOL a partir das atividades feitas por eles em sala. Restringimos, assim, nossa investigação neste texto, ao recorte das respostas a estas três perguntas:

a) pergunta 3 - Você acredita que as atividades de monitoria no PFOL são importantes para sua formação? Comente.

b) pergunta 5 - Desde o começo das atividades de monitoria até o presente momento, você pensa que houve alguma mudança em você com relação à sua formação? Explique.

c) pergunta 6 - O que você aprendeu/aprende participando das atividades de monitoria com os alunos estrangeiros? De que forma elas colaboraram/colaboram para a sua formação acadêmica, profissional e pessoal?

As três perguntas apresentam desdobramentos da construção de ser professor, que é o que se pretende com as práticas oferecidas pela monitoria. Entendemos, conforme já apontamos neste texto, que a formação do professor passa pela aprendizagem situada e pela construção de postura reflexiva como professores em formação desde o começo do curso, considerando que essa construção se dá no mundo que é estruturado social e culturalmente. Assim, conforme apresentação em nossa seção teórica, estamos orientados por Schneider (2006); Lave e Wenger (1991); Johnson e Golombek (2016); Gimenez (2005); Halu (2010); Zamboni (2013); Pérez Gómez (1992) e Schon (1992). 
Dividiremos nossa análise de maneira a focar as quatro respostas às três perguntas isoladamente e, depois, analisá-las de maneira global buscando compreendê-las em conjunto. Passamos, portanto, a discorrer sobre a pergunta 3.

Quadro 2 - Respostas da pergunta 3.

\begin{tabular}{|c|c|}
\hline \multicolumn{2}{|r|}{$\begin{array}{l}\text { Pergunta 3: Você acredita que as atividades de monitoria no PFOL são importantes para sua formação? } \\
\text { Comente. }\end{array}$} \\
\hline M1 & $\begin{array}{l}\text { Como a participação nesse grupo demanda observação nas aulas ao menos } 2 \text { vezes na se- } \\
\text { mana, assim como há possibilidade de regência ao menos uma vez por semestre, acredito que } \\
\text { o PFOL contribui muito na minha formação como professora, principalmente de língua es- } \\
\text { trangeira, mas também possibilita desenvolver e pensar linguisticamente no português como } \\
\text { língua materna. }\end{array}$ \\
\hline M2 & $\begin{array}{l}\text { A observação e atuação em salas de aula de PFOL proporciona as mais diversas reflexões so- } \\
\text { bre a língua materna, que muitas vezes não são realizadas durante o curso, além de também } \\
\text { contar com o conhecimento e aproximação com realidades distintas. }\end{array}$ \\
\hline M3 & $\begin{array}{l}\text { Além de ter acesso ao plano de aula, também ajuda muito acompanhar a aplicação desse } \\
\text { plano em sala, vendo como os alunos respondem aos exercícios e discussões. Ter vivência } \\
\text { dentro de uma sala com os mais diferentes alunos ajuda muito a pensar em como ensinar o } \\
\text { PT como língua estrangeira. }\end{array}$ \\
\hline M4 & $\begin{array}{l}\text { Elas nos auxiliam a ter um primeiro contato com o contexto de sala de aula sem necessaria- } \\
\text { mente nos atribuir a grande responsabilidade de assumir uma turma como professor regente. } \\
\text { No lugar, aos poucos nos preparam a partir do contato com os alunos e reflexões a partir das } \\
\text { questões apresentadas para termos uma responsabilidade maior em sala. }\end{array}$ \\
\hline
\end{tabular}

Fonte: as autoras (2020).

A partir das respostas, é possível afirmar que todos os participantes da pesquisa entendem o PFOL como um lugar de construção de identidade como professor. Três deles enunciam discursivamente que o espaço do PFOL faz com que eles reflitam sobre o português. Esse aspecto se depreende destes excertos: "também possibilita desenvolver e pensar linguisticamente no português como língua materna."; "Ter vivência dentro de uma sala com os mais diferentes alunos ajuda muito a pensar em como ensinar o P'T como língua estrangeira." "A observação e atuação em salas de aula de PFOL proporciona as mais diversas reflexões sobre a língua materna". (grifos nossos) Se voltamos ao quadro com as informações dos participantes, poderemos notar que somente um deles (M3) já estava na segunda metade do curso de Letras (que é de 8 semestres e esse participante estava no $5^{\circ}$.). Os demais ainda não haviam cursado as disciplinas em que o contato com aulas e a sala de aula (práticas e estágios) é mais intenso. A possibilidade de reflexão na ação - definida por Schön - fica patente aqui, uma vez que é a partir da vivência da sala de aula 
que as questões de estrutura e uso do português aparecem. Note-se que M2 escreve que a atuação no PFOL proporciona reflexões “que muitas vezes não são realizadas durante o curso". É nesse espaço situado de aprendizagem (SCHNEIDER, 2006) que se constroem as relações da docência - ensino e aprendizado - a partir de situações de interação reais.

Três deles (M2, M3 e M4) apontam para a importância do contato com os alunos estrangeiros, sendo que, para M4, o contato com os alunos e a preparação aos poucos para a participação mais ativa ("responsabilidade maior") em sala de aula é um ponto positivo da monitoria. M2 retrata a aproximação a realidades distintas (dos alunos estrangeiros), o que é corroborado pela visão de M3, que indica a importância na sua formação da vivência na sala de aula com os mais diferentes alunos. Nesse ponto, relembramos a colocação de Schneider (2006) acerca do aprendizado formado na monitoria, a partir da interação com a diversidade.

Em todas as repostas, podemos identificar a constatação da importância da monitoria em dois aspectos: um que tem mais relação com questões linguístico-discursivas em português (a reflexão sobre formas e usos da língua portuguesa) e outro que corresponde ao trabalho pedagógico que surge na interação da sala de aula, interação essa que é composta pelos distintos agentes típicos das práticas sociais.

$\mathrm{Na}$ pergunta seguinte, nosso interesse era o de observar o que eles identificavam ter construído durante o processo.

Quadro 3 - Respostas da pergunta 5.

\begin{tabular}{|c|c|}
\hline \multicolumn{2}{|r|}{$\begin{array}{l}\text { Pergunta 5: Desde o começo das atividades de monitoria até o presente momento, você pensa que houve } \\
\text { alguma mudaça em você com relação à sua formação? }\end{array}$} \\
\hline M1 & $\begin{array}{l}\text { Com certeza, aprendi a planejar minhas aulas de maneira adequada, considerando o contexto } \\
\text { dos alunos e a função das atividades com que tratamos no PFOL. Também me sinto muito } \\
\text { mais tranquila ao entrar na sala de aula no geral, até mesmo na desenvoltura de trabalhos no } \\
\text { curso de Letras. }\end{array}$ \\
\hline M2 & $\begin{array}{l}\text { Participar da produção de materiais didáticos para as aulas, bem como a elaboração de provas, } \\
\text { critérios de correção e até mesmo regências, afetam todos os momentos em que preparo materi- } \\
\text { ais para minhas aulas de português/inglês }{ }^{3} \text {, bem como nos demais momentos da prática peda- } \\
\text { gógica, além de também influenciar na visão sobre diferentes matérias presentes no curso. }\end{array}$ \\
\hline
\end{tabular}

${ }^{3}$ M2 menciona que as atividades que permeiam a monitoria o auxiliam nas preparações de aula de português e inglês, porém, anteriormente, ele havia informado que não possuía experiência formal como docente. Arriscamo- 


\begin{tabular}{|c|l|}
\hline M3 & $\begin{array}{l}\text { A forma como eu vejo a língua portuguesa mudou muito. Hoje em dia eu me questiono muito } \\
\text { sobre sua estrutura e seu uso. Principalmente como eu poderia ensinar isso para um aluno es- } \\
\text { trangeiro. }\end{array}$ \\
\hline M4 & $\begin{array}{l}\text { Por conta da minha experiência com a monitoria desde o início da graduação, acredito que di- } \\
\text { versos dos desafios encontrados por meus colegas, em relação tanto a conteúdos práticos } \\
\text { quanto teóricos, para mim se mostravam menos problemáticos uma vez que já havia tido con- } \\
\text { tato com eles em sala de aula. Acredito também que grande parte da atitude que hoje tenho } \\
\text { como professora em formação nasceu graças ao meu contato com a sala de aula na monitoria. }\end{array}$ \\
\hline
\end{tabular}

Fonte: as autoras (2020).

Entre as respostas apresentadas, aparecem modificações de diversas naturezas. Enquanto M1, M2 e M3 focaram as respostas em questões mais relacionadas à preparação das aulas - seja no processo de planejamento e organização, seja na elaboração das atividades - M4 revelou a relação com a sala de aula como sendo a construção mais significativa no processo da monitoria. Sabendo que M3 já tinha experiência como voluntária de produção textual em cursinho para exames e seleção (ENEM e vestibular), é interessante observar que, em sua resposta, aparecem textualmente modificações no modo de pensar o português (tanto forma quanto usos) e também o ensino dessa língua como segunda/estrangeira/adicional. Não estaríamos erradas em dizer que essa participante pôde crescer no entendimento de português na medida em que já tendo tido alunos brasileiros, veio a se deparar com um público de estrangeiros. Tal fato ilustra e reforça a perspectiva da aprendizagem situada. De acordo com o que vimos na seção teórica, a aprendizagem situada, segundo Lave e Wenger (1991), está fundada no agir entre pessoas e ambiente. Nela, os processos de participação vão (com)formando o conhecimento produzido. A comunidade de prática formada a partir da monitoria, em uma situação específica e contingente promove a elaboração da aprendizagem, que segundo os mesmos autores, demanda tempo e práticas sociais em um grupo determinado.

M2 considera que a monitoria no PFOL foi tão importante para sua formação como professor, que complementa tópicos de outras disciplinas do curso de Letras. Para ele, uma 
ação formativa (como é o caso da monitoria) estende-se a outros componentes do curso de Letras, uma vez que todos estão vinculados a um curso de licenciatura.

É curioso observar que, embora encontremos pontos de contato entre as respostas, também é possível verificar identidades particulares em cada um dos participantes; isso porque mesmo que façam parte de uma comunidade de prática que partilha de determinados valores e opiniões, também há espaço para a individualidade. Em todos eles, pode-se identificar pontos particulares. Se fôssemos colocar em palavras ou expressões-chave as respostas dos participantes, elas poderiam ser:

Quadro 4 - Palavras chave das respostas 3 e 5, organizadas por participantes

\begin{tabular}{|l|l|}
\hline M1 & Planejamento, tranquilidade, desenvoltura \\
\hline M2 & Processo da organização do curso e das aulas, influência na visão do Curso de Letras \\
\hline M3 & Questionamento sobre formas e uso do português e seu ensino \\
\hline M4 & Experiência constituída a partir da monitoria no PFOL e formação de atitude como professor \\
\hline
\end{tabular}

Fonte: as autoras (2020).

Todos eles observam mudanças comuns no processo, mas também revelam singularidades. Assim, é possível relembrar a compreensão de Halu (2010) sobre a atitude do professor reflexivo: as respostas refletem pensamentos independentes/sozinhos, mas que se encontram em alguns momentos porque, afinal, todos fazem parte de um grupo maior que discute ideias semelhantes.

Vejamos agora as respostas à questão mais direta sobre a aprendizagem na monitoria e a relação com sua formação:

Quadro 5 - Respostas da pergunta 6

\begin{tabular}{|c|l|}
\hline \multicolumn{2}{|c|}{ Pergunta 6 - O que você aprendeu/aprende participando das atividades de monitoria com os alunos estran- } \\
geiros? De que forma elas colaboraram/colaboram para a sua formação acadêmica, profissi- \\
onal e pessoal?
\end{tabular}




\begin{tabular}{|c|l|}
\hline M3 & $\begin{array}{l}\text { Com as atividades de monitoria eu fui capaz de acompanhar os diferentes passos que envolvem } \\
\text { dar PT como língua estrangeira. Desde a elaboração do plano, dos exercícios e material de } \\
\text { apoio, até sua aplicação em sala bem como dar aulas ou ajudar em alguma atividade e/ou expli- } \\
\text { cação. }\end{array}$ \\
\hline M4 & $\begin{array}{l}\text { Algumas das coisas que acredito mais terem sido desenvolvidas nesse período foram a lida com } \\
\text { e a observação dos alunos em sala de aula. Saber interpretar suas expressões, procurar entender } \\
\text { e atender suas necessidades na língua, construir um ambiente saudável e aberto ao diálogo e, } \\
\text { por fim, ter empatia. }\end{array}$ \\
\hline
\end{tabular}

Fonte: as autoras (2020).

M1 e M4 atentaram mais para a relação da necessidade do aprendizado por alunos de diferentes contextos, à importância da aprendizagem de português para eles e M4, inclusive, usa a palavra "empatia" como uma das elaborações da monitoria. M1 é mais explícito porque menciona que há refugiados entre os alunos estrangeiros e diz que percebe a relação direta entre ensino-aprendizagem de português e as necessidades dos estudantes. Isso evidencia a preocupação do professor em adequar as atividades didático-pedagógicas a seu público contemplando também os usos que este precisa e/ou quer fazer. Aqui, podemos relacionar diretamente o que propõe Halu (2010) quando discorre sobre a capacidade de enfrentar situações diárias resultado dessa experiência adquirida em sala de aula.

Embora M2 não tenha exemplificado uma atividade ou uma prática, podemos depreender de sua resposta o que Schon (1992) chama de reflexão sobre reflexão na ação: "Cada explicação que damos como monitores em sala acaba influenciando em nossa prática fora dali (...)".

\section{Considerações finais}

Neste estudo, apresentamos parte do trabalho desenvolvido pelo PFOL da UTFPRCT, a partir da perspectiva de alunos-monitores - licenciandos em Letras Português Inglês - participantes do Programa PFOL - quando questionados sobre a influência da participação no projeto na sua própria formação como professores de línguas. Para isso, dividimos nosso texto em seções que pudessem retomar conceitos legais e institucionais sobre monitoria; apresentar a visão que orienta nosso trabalho com formação de professores; 
contextualizar nosso trabalho no âmbito do PFOL na UTFPR-CT, expor metodologicamente o recorte da pesquisa aqui realizada e discutir e analisar os dados gerados por meio de questionários com os monitores, à luz da teoria enunciada.

Desse modo, recorremos à Lei de Diretrizes e Bases da Educação Nacional (LDB), no 9394 - de 20 de dezembro de 1996 - que atualiza o significado de monitoria, relacionando-o à formação profissional do graduando e também a informações institucionais, especialmente o da UTFPR, que organiza a monitoria e esclarece seus objetivos, que não só estão relacionados à experiência acadêmica e à formação profissional, como também ampliam a perspectiva para uma formação cidadã. Logo em seguida, explicitamos nosso fazer na monitoria específica em PFOL, para então retomar conceitos de aprendizagem situada e prática reflexiva em todos os processos de aprendizagem desses monitores preparando-se para serem professores e forjando-se como tal.

Acreditamos no trabalho pedagógico, oriundo da formação de professores que privilegia o contato com a sala de aula desde o primeiro momento e que faz isso considerando a prática assistida, de tal modo que os monitores sintam-se encorajados a desenvolver reflexão e autonomia ao mesmo tempo em que são assistidos por professores mais experientes. Esse acompanhamento acontece tanto em sala como fora dela, em outras atividades formativas, o que leva à construção de uma comunidade de prática.

Para identificarmos como os alunos-monitores têm significado essas práticas, recorremos a diferentes instrumentos de pesquisa. O recorte que narramos, neste estudo específico, é fruto de dados gerados por meio de questionário aberto escrito, cujos dados comprovam que os alunos-monitores entendem a participação no PFOL como importante em sua formação. Podemos afirmar que tal postura se observa na ótica do português como língua não-materna, cujas reflexões emergem do contato com os alunos estrangeiros. Esse contato, no entanto, revela um impacto não só em construtos do português como língua não-materna, mas também do português como língua materna. Outro ponto a ser destacado e que está de acordo com um dos objetivos da monitoria da UTFPR é a formação não só do profissional, mas também a formação cidadã: o contato com os estrangeiros faz 
com que os alunos-monitores reflitam sobre a situação em que aqueles se encontram, especialmente os de maior vulnerabilidade social. É também nesse olhar, para além da formação teórico-pedagógica, que nos interessa contribuir.

Esperamos que este estudo possa fomentar o debate acerca da formação de professores a partir da monitoria. Contribuindo, dessa forma, para a construção de um olhar mais generoso sobre o quanto os alunos de Letras, ainda no começo de sua formação inicial, podem participar ativamente de processos de ensino-aprendizagem que os auxiliem na construção do ser professor, bem como que ajudem professores formadores a continuar sua jornada de modo reflexivo, em suas práticas. E esperamos também demonstrar como, a monitoria integrada a este programa de extensão específico (PFOL-UTFPR-CT) pode contribuir para a construção da proficiência linguística dos alunos estrangeiros, de modo a integrar as comunidades interna e externa da universidade pública.

\title{
IN CLASS MONITORSHIP: A TEACHER TRAINING INICIATIVE
}

\begin{abstract}
The present text analyzes responses from students of the Portuguese-English course, who acted as in class student-monitors in Portuguese for Speakers of Other Languages (PFOL), from the Federal University of Technology - Paraná, Campus Curitiba (UTFPR-CT). The article seeks to identify the views of student-monitors on the relevance of their participation in the monitorship of PFOL-UTFPR-CT. For this, we organized the text as follows: first, we present the organization of the article, expressing the general idea and exposing the parts that integrate this study. Then, we discuss legal and institutional texts on monitorship and give voice to our perspective of working with in class monitorship. In addition, we establish relationships between monitorship and teacher training by taking into account Lave and Wenger (2001) and Johnson and Golombek (2016) works regarding situated learning; Schön (1992), Pérez Gómez (1992), Gimenez (2005), Halu (2010) and Zamboni (2013) on their views on reflective teacher and, more specifically, the concepts of reflection in action and reflection on reflection in action, by Schön (1992). The methodology used was an open questionnaire, with 12 questions, from an interpretive perspective (LESSA DE OLIVEIRA, 2008; NEVES, 2015). The analyzes reveal that the monitorship is embedded in the theoretical and practical subjects of the undergraduation course of Portuguese and English (which, many times, are not addressed within the course's syllabus). In addition, although we find converging points between the responses, we also observe particular identities in each of them.
\end{abstract}

KEYWORDS: PFOL; In class monitorship; Teacher's identities; Teacher training. 


\section{REFERÊNCIAS}

ALMEIDA, Elizabeth G. de. Tese de Doutorado: Aprendizagem situada e letramentos digitais no estágio supervisionado de espanhol. Belo Horizonte: Universidade Federal de Minas Gerais, 2013.

BALDIN, Fernanda D. C.; CORDEIRO, Elisa N. O Processo de Formação Inicial de Professores de Português para Falantes de Outras Línguas na UTFPR-CT: Integração entre Prática Pedagógica e Teoria. Em: Revista Linguas e Letras, v. 18, n. 39, 2017.

BECKER, Marcia Regina; BORK, et. all. O desafio do ensino de português para falantes de outras línguas - PFOL - na UTFPR. Em: Anais do $1^{\circ}$ SEI - Seminário de Extensão e Inovação da UTFPR, Curitiba, 2011.

BRASIL. DECRETO No 3.847, DE 25 DE JUNHO DE 2001. IPI incidente sobre os produtos que menciona, Brasília, DF, mar 2017. Disponível em: < http:/ /www.imprensanacional.gov.br/mp_leis/leis_texto.asp?ld=LEI\%209887>. Acesso em: 12 out. 2017.

BRASIL. Documento legislador das Atividades do Ensino Superior. Lei No 5.540, de 28 de novembro de 1968. Disponível em: <http://www.planalto.gov.br/ccivil_03/Leis/L5540.htm>. Acesso em: 14 abr.2020.

BRASIL. Lei de Diretrizes e Bases da Educação Nacional. Brasília, DF, 20 dez 1996. Disponível em: http://www.planalto.gov.br/ccivil_03/Leis/L9394.htm\#art92 Acesso em: 14 abr.2020.

BRASIL. Regulamento do Programa de Monitoria da UTFPR. Disponível em: http:/ /www.utfpr.edu.br/estrutura-universitaria/pro-reitorias/prograd/programas-academicos/monitoria/arquivos/RegulamentoProgramadeMonitoria.pdf. Acesso em: 14 abr.2020.

CELANI, M.A.A. Questões de ética na pesquisa em Linguística Aplicada. Linguagem \& Ensino, 2005, vol.8 n.1, jan/jun., p.101-122.

FARIA, J.P. A monitoria como prática colaborativa na universidade. Dissertação de Mestrado. Programa de Pós-Graduação em Linguística Aplicada e Estudos da Linguagem. Pontifícia Universidade Católica de São Paulo, 2003.

GIMENEZ, Telma. Desafios contemporâneos na formação de professores de língua: contribuições da linguística aplicada. In: FREIRE, Maximina; VIEIRA ABRAHÃO, Maria Helena; BARCELOS, Ana Maria Ferreira (Orgs). Linguística aplicada e contemporaneidade. Campinas: Pontes, 2005.

HALU, Regina. Tese de Doutorado: Formação de formadoras de professoras de inglês em contexto de formação continuada (NAP-UFPR). Universidade Federal do Paraná, Curitiba, 2010.

JOHNSON, Karen E.; GOLOMBEK, Paula R. Mindful L2 teacher education. New York: Routledge, 2016. 
LAVE, J.; WENGER, E. Situated learning: legitimate peripheral participation. New York: Cambridge University Press, 1991.

LESSA DE OLIVEIRA, Cristiano. Um apanhado teórico-conceitual sobre a pesquisa qualitativa: tipos, técnicas e características. Revista Travessias, v.2, n.3, 2008.

NEVES, Miranilde Oliveira. A importância da investigação qualitativa no processo de formação continuada de professores: subsídios ao exercício da docência. In Revista Fundamentos, v.2, n.1, 2015, p. 17-31

SCHNEIDER, M.S.P.S. Monitoria: instrumento para trabalhar com a diversidade de conhecimento em sala de aula. Revista Espaço Acadêmico (UEM), v. Mensal, p. 65, 2006.

Recebido em: 30/04/2020.

Aprovado em: 27/05/2020. 